\section{Does latent learning produce instantaneous transfer of place navigation?}

\author{
J. R. KEITH \\ University of Colorado, Boulder, Colorado
}

In their commentary concerning the findings of Keith and McVety (1988), Chew, Sutherland, and Whishaw (1989) claim that "latent learning does not produce instantaneous transfer of place navigation" (p. 207). This statement leads me to suspect that the terminology used to express our views of spatial learning and memory has given rise to more confusion than clarity. This is unfortunate, since our common goal is to reveal the processes that result in spatial learning and memory. I feel obliged to respond to Chew and his colleagues, not only because they have inaccurately portrayed the viewpoint presented in their own previous work (Sutherland, Chew, Baker, \& Linggard, 1987), but also because they have misrepresented some of the findings of Keith and McVety.

Sutherland and Linggard (1982) found that naive rats that had been allowed to view an environment from the location of an escape platform located the platform from a distal starting point more readily than did animals that had not been exposed to the platform. These data were seen as evidence that animals can learn about the location of a goal without actually engaging in goal-searching behavior. However, in their experiment, these "latent learners" took about 10 times longer to find the escape platform than did a well-trained rat (one that had received extensive training in swimming to the platform from a variety of starting positions). In addition, the rats that had the experience of standing on the platform showed only a small improvement in their latencies to locate the platform, compared with the performance of rats that did not stand on the platform. Nevertheless, their animals did, in fact, learn something that allowed them to locate the escape platform with shorter latencies.

In contrast to the findings of Sutherland and Linggard (1982), Sutherland et al. (1987), claimed that

in order to exhibit transfer of efficient place navigation from a novel starting location in this situation, it is necessary during training for the rats to (1) be familiar with the distal cues viewed from the starting region of the novel starting location, and (2) swim through the vicinity of the novel starting location. (p. 56)

Sutherland et al. (1987) attributed the "latent learning" effect observed by Sutherland and Linggard (1982) to the fact that all of the subjects in the earlier study had been allowed to swim around the pool prior to being allowed to observe the environment from the escape platform.

Correspondence may be addressed to J. R. Keith, Department of Psychology, University of Colorado, Boulder, CO 80309.
The view proposed by Sutherland et al. (1987) is based on an experiment in which the experience of the animals in a water maze was restricted by a Plexiglas barrier to one side of the pool. These subjects' ability to locate the platform was poor when they were released from starting locations on the side of the pool in which they had no prior swimming experience. We were especially intrigued by Figure 3 of Sutherland et al.'s manuscript, which shows that the rats in this condition navigated poorly even when they reached the side of the pool in which they had received extensive previous training. This led us to suspect that perhaps their methodology actually obscured the spatial cognitive capacities they were attempting to measure.

In our experiment (Keith \& McVety, 1988), animals received 3 days of training ( 10 trials per day) in a water maze so they could master the procedural aspects of the water-maze task. On the 4th day, the animals were tested in a maze located in a different room. The subjects that were permitted to view the environment from the location of the escape platform subsequently located the platform more quickly than did the subjects that had not viewed the room from the location of the platform. This improvement was observed despite the fact that the animals had received no previous experience in the test room aside from standing on the escape platform for $120 \mathrm{sec}$ prior to testing.

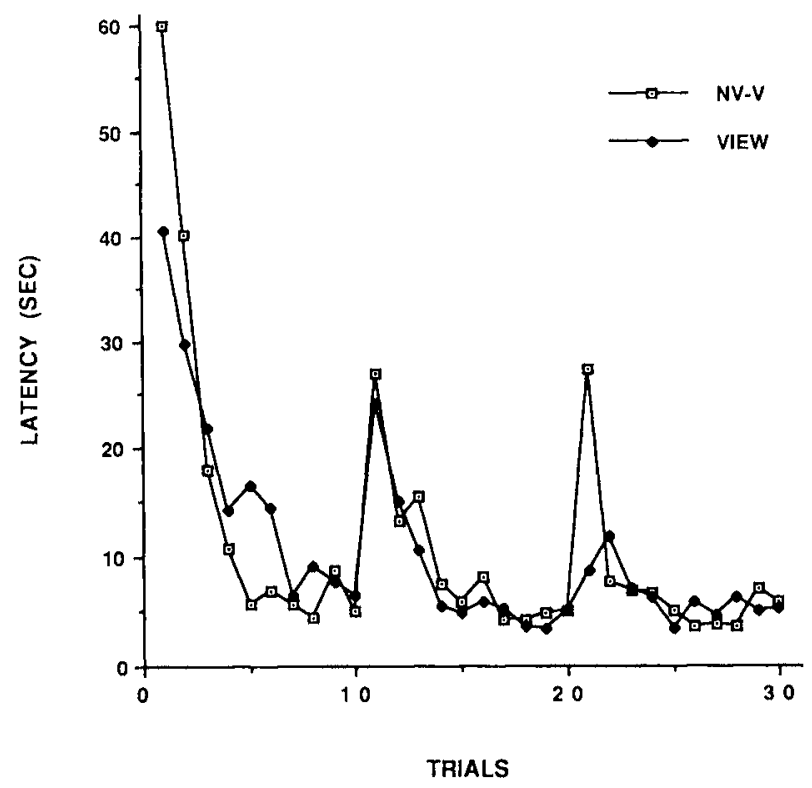

Figure 1. Latencies to locate the escape platform during Phase 1 training for Group VIEW (consisting of the combined means of Groups V-V, V-180, and V-NV) and Group NV-V. (From "Latent place learning in a novel environment and the influence of prior training in rats," by J. R. Keith and K. M. McVety, 1988, Psychobiology, 16, 146-151. Copyright 1988 by Psychonomic Society, Inc.) 


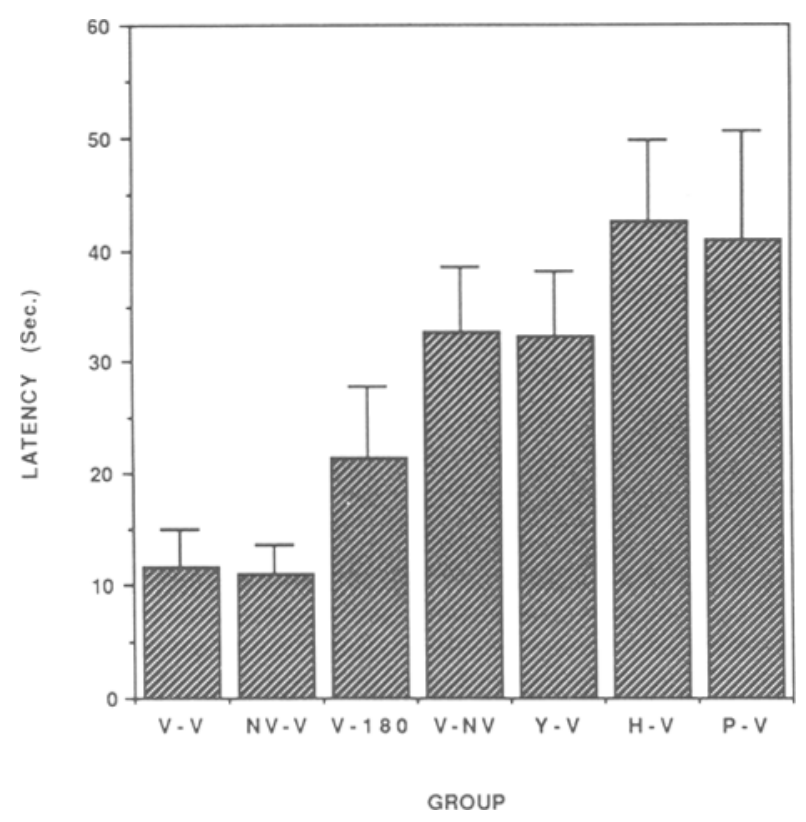

Figure 2. Latencies to locate the escape platform on the test trial in the novel environment for all groups. (From "Latent place learning in a novel environment and the influence of prior training in rats," by J. R. Keith and K. M. McVety, 1988, Psychobiology, 16, 146151. Copyright 1988 by Psychonomic Society, Inc.)

In their rejoinder, Chew et al. (1989) argue that the rats in our study did not navigate accurately to the platform during the test situation. They base this view primarily on the discrepancy in the subjects' escape latencies between the two pools. In their rejoinder, Chew and his colleagues refer to Figure 2 of our previous report (Keith $\&$ McVety, 1988) as evidence that our well-trained rats navigated accurately to the escape platform in about $4 \mathrm{sec}$. However, even after extensive training, our subjects required approximately $7 \mathrm{sec}$ to locate the platform, even in the familiar room. Apparently, Chew et al. have failed to recognize three important factors concerning the socalled "increased latency problem." First, the subjects in their experiments were more than twice as large as the rats used in our study. The difference in latencies to locate the platform, which is the foundation of their criticism of our experiment, can probably be accounted for simply by the difference in the sizes of the subjects used in the two studies.
Second, our subjects did not show latencies during the test situation (in the novel room) that were "two to three times longer than would be expected for accurate navigators swimming in familiar surroundings" (Chew et al., 1989 , p. 208), as they claim. "Two to three times" would be accurate if it read " 2 to $3 \mathrm{sec}$ " in their rejoinder. Furthermore, Chew et al. ask, "Why should rats swim faster in a familiar setting and slower in the novel one if they are presumed to be equally adept?'" (p. 208). In fact, our rats' performance was not slower in the novel setting, as can be seen by comparing the latencies of the first trial of Day 3 of training in the familiar room for the VIEW condition with the test trial the next day in the novel room for the NV-V and V-NV conditions, shown in Figures 1 and 2 . In both cases, our subjects located the platform in approximately $10 \mathrm{sec}(9.5 \mathrm{vs} .10 .2 \mathrm{sec})$.

Finally, Chew et al. (1989) imply that our subjects did not demonstrate "truly knowledgeable navigation," and they hold that such navigation requires "detailed information from experienced local views and routes" (p. 209). If navigation in Groups NV-V and V-V of our study (Keith \& McVety, 1988) were not guided by "true" knowledge concerning the location of the platform, we can only wonder how viewing the room from the escape platform led to (1) a three-fold reduction in latency to locate the platform, and (2) an increase in the proportion of the subjects that initiated their search in the quadrant that contained the escape platform (see Keith \& McVety, 1988, Figure 4). Did the animals learn about the location of the escape platform while they were viewing the room from the platform? I am delighted that the reader can form his or her own opinion about this issue.

\section{REFERENCES}

Chew, G. L., Sutherland, R. J., \& Whishaw, I. Q. (1989). Latent learning does not produce instantaneous transfer of place navigation: A rejoinder to Keith and McVety. Psychobiology, 17, 207-209.

KerTH, J. R., \& MCVETY, K. M. (1988). Latent place learning in a novel environment and the influences of prior training in rats. Psychobiology, 16, 146-151.

Sutherland, R. J., Chew, G. L., Baker, J. C., \& Linggard, R. C. (1987). Some limitations on the use of distal cues in place navigation by rats. Psychobiology, 15, 48-57.

Sutherland, R. J., \& LingGard, R. (1982). Being there: A novel demonstration of latent spatial learning in the rat. Behavioral \& Neural Biology, 36, 103-107.

(Manuscript received December 13, 1988; revision accepted for publication February 22, 1989.) 